\title{
Effect of electrolytes on electrochromic properties and morphology of poly(2,5-dimethoxy aniline) films
}

\author{
BUREERAT SUEPHATTHIMA ${ }^{1}$, NOPHAWAN PARADEE ${ }^{1}$, ANUVAT SIRIVAT ${ }^{1, *}$ and \\ DATCHANEE PATTAVARAKORN ${ }^{2}$ \\ ${ }^{1}$ The Petroleum and Petrochemical College, Chulalongkorn University, Bangkok 10330, Thailand \\ ${ }^{2}$ Department of Industrial Chemistry, Faculty of Science, Chiang Mai University, Chiangmai 50200, Thailand
}

MS received 21 August 2013; revised 17 October 2013

\begin{abstract}
Poly(2,5-dimethoxyaniline) (PDMA) was electrochemically synthesized in oxalic $\left(\mathrm{H}_{2} \mathrm{C}_{2} \mathrm{O}_{4}\right)$ nitric $\left(\mathrm{HNO}_{3}\right)$ and hydrochloric $(\mathrm{HCl})$ acids and deposited onto flexible indium tin oxide at various synthesis times and deposition potentials as electrochromic materials. The PDMA films were characterized by FT-IRspectrometry, scanning electron microscopy, UV-Vis spectrophotometry and cyclic voltammetry. All PDMA films show reversible colour changes from yellow to green corresponding to the transition from the fully reduced state to the fully oxidized state under potential switching. The surface morphology and thickness of PDMA films depend critically on the type of acids used in the electrochemical polymerization process. The morphology of PDMA are highly porous microfibres $\left(\mathrm{H}_{2} \mathrm{C}_{2} \mathrm{O}_{4}\right.$ and $\left.\mathrm{HNO}_{3}\right)$, tiny granular aggregate $(\mathrm{HCl})$ and particle agglomerate depending on the polymerization time. The fastest response time observed via colour changing of $3.7 \mathrm{~s}$ is obtained from the HCl-PDMA film at 3.5 volt and at the synthesis time of 6 min, as primarily due to the thickness of the film. The flexible PDMA film is demonstrated here as a potential candidate to be used in electrochromic devices.
\end{abstract}

Keywords. Electrochromic polymer; poly(2,5-dimethoxyaniline); electrochemical polymerization; response time.

\section{Introduction}

Conductive polymers continue to gain growing interest, because they are widely used in many applications: optical displays, rechargeable batteries, electrochromic devices and light emitting diodes (Ramakrishnan 1997). Among organic molecules, conductive polymers have attracted significant interest in the field of electrochromism.

Electrochromism is defined as a reversible and visible change in its transmittance and/or reflectance of electrochromic materials as a result of an oxidation-reduction reaction. The applications for such materials are mirrors of vehicles (Sonmez 2005), smart windows (Kim et al 2009), electrochromic displays (Bange 1999), earth-tone chameleon materials (Brotherson et al 1999), ink-jet printers and most recently E-paper (Peters and Freeman 1991).

Earlier reports (Sonmez 2005) indicated that the use of inorganic compounds or the metal oxides, iridium dioxide $\left(\mathrm{IrO}_{2}\right)$ and tungsten trioxide $\left(\mathrm{WO}_{3}\right)$, which were mixedvalence metal complexes. However, these transition metal oxides electrochromically exhibited a slow response time (tens of seconds) and a high processing cost. Compared

*Author for correspondence (anuvat.s@chula.ac.th) with electrochromic polymers, they have several merits: low processing cost, low power requirement during switching, low operating voltage, repeatability, high colouration efficiency, good UV stability, fast switching ability and fine-tuning ability of the band gap via modification of chemical structure of the polymer. Additionally, there is no dependence on the angle of vision (Sonmez 2005).

Potential conducting polymers are comprised of a number of functionalized groups such as polypyrroles, polythiophenes, polyanilines, etc. (Sapp et al 1998). They have been recognized as an interesting class of electrochromic materials. An important issue of electrochromic polymers has been that of controlling their colours by main-chain and pendant-group structural modifications.

Polyaniline (PANI) is one of the most promising conducting polymers due to an easy polymerization process and excellent chemical stability, combined with relatively high levels of conductivity (Khan et al 2003). Poly(2,5dimethoxyaniline), or PDMA, is the derivative of PANI which shows higher solubility and faster response time than PANI. PDMA film can make reversible colour changes from yellow to green representing a switch between the reduced state to the oxidized state through an application of electrical potential faster than that of PANI (Sun et al 2013). Cyclic voltammetry results have also 
confirmed that PDMA can be easily switched from the leucoemeraldine state to the emeraldine state. PDMA also shows a shorter response time (9s) than the electrochemically prepared PANI (22 s) (Huang et al 2002).

Normally, the electrochromic materials are produced in the form of thin film. They can be produced by many methods including electron beam deposition, chemical vapour deposition, the Langmuir-Blodgett technique and the layer-by-layer self-assembly technique (Sarkar et al 2000). In the case of electronically functional thin films, thinner films are generally preferred due to the shorter electron and ion transport path length (Montazami et al 2010).

The purpose of this work was to polymerize 2,5dimethoxyaniline (DMA) via electrochemical polymerization on indium tin oxide (ITO) plastic submerged in oxalic, nitric and hydrochloric acids at various synthesis times (3, 6 and $10 \mathrm{~min}$ ) and applied potentials (1 and $1.5 \mathrm{~V})$. This study was also intended to investigate the effect of various electrolytes on the electrochromic properties of PDMA film due to different doping characteristics. The PDMA films were characterized for the electrochromic properties using a UV-Visible spectroelectrometer. Fourier-transform infrared spectrometer and thermogravimetric analyser were also utilized to investigate the chemical and thermal properties of PDMA film, respectively. The morphology and thickness of the PDMA coated ITO surface were studied by scanning electron microscope. Cyclic voltammetry was used to study the oxidation-reduction properties of the PDMA/ITO plastic.

\section{Experimental}

\subsection{Materials}

The starting monomer, 2,5-dimethoxy aniline (DMA), was purchased from Sigma Aldrich (AR grade, 98\%). Oxalic acid (Ajax Finechem, AR grade), hydrochloric acid (Lab Scan, AR grade, 37\%), sulfuric acid (Lab Scan, AR grade, 98\%), nitric acid (Lab Scan) and acetic acid (Lab Scan) were used for the synthesis without further purification. An ITO-coated PET substrate (60 $\Omega$ ) was purchased from Sigma Aldrich.

\subsection{Electrochemical polymerization of PDMA on ITO plastic}

PDMA was electrodeposited onto the ITO plastic using potentials of $1 \mathrm{~V}$ and $1.5 \mathrm{~V}$, in either $25 \mathrm{~mL}$ of $0.1 \mathrm{M}$ DMA in $0 \cdot 1 \mathrm{M}$ oxalic acid, hydrochloric acid, or nitric acid, and at various deposition times of 3, 6 and $10 \mathrm{~min}$. Stainless steel and ITO plastic were used as the counter and the working electrodes, respectively.

\subsection{Characterization of PDMA/ITO film}

Infrared absorption spectra of PDMA were taken to study the chemical structure of PDMA. A Fourier transform infrared spectrometer (FT-IR; Thermo Nicolet, Nexus 670) was used in the absorption mode with 64 scans, covering a wavenumber range of $4000-400 \mathrm{~cm}^{-1}$. Optical grade $\mathrm{KBr}$ was used as the background material.

A thermogravimetric analyser (TGA; Perkin Elmer, TGA7) was used to study the thermal stability and to determine the decomposition temperature of PDMA. The experiment was carried out by electrochemical polymerization of the DMA monomer in each acid solution on a stainless steel electrode for $20 \mathrm{~min}$. Then, the PDMA coated stainless steel electrodes were dried and PDMA was scrapped into a powder, kept at $105^{\circ} \mathrm{C}$ overnight, and later used for TGA measurements. The sample (2$3 \mathrm{mg}$ ) was weighed and then placed it in an alumina pan and heated under nitrogen atmosphere with a heating rate of $10^{\circ} \mathrm{C} / \mathrm{min}$ from 50 to $900{ }^{\circ} \mathrm{C}$.

The synthesized PDMA/ITO films were characterized for redox properties with a cyclic voltammetry using a multi-channel potentiostat (VMP, Bio Logic Science Instrument). Measurements were carried out in $200 \mathrm{~mL}$ of $0.01 \mathrm{M} \mathrm{H}_{2} \mathrm{SO}_{4}$ solution as the background electrolyte, assembled with a three-electrode cells consisting of a saturated calomel electrode (SCE) as the reference electrode, a stainless-steel wire as the counter electrode, with a $2 \mathrm{~cm}^{2}$ PDMA/ITO plastic stub used as the working electrode. The cyclic voltammogram $(\mathrm{CV})$ of the PDMA/ITO electrodes was measured in the potential range of -1 to $+1.5 \mathrm{~V}$ and vs SCE. The parameters and cell characteristics were setup as follows: a scan rate $(\mathrm{d} E / \mathrm{d} t)$ of $10 \mathrm{mV} / \mathrm{s}$, $\mathrm{d} E_{\mathrm{R}}=1 \mathrm{mV}$, with an electrode surface area of $2 \mathrm{~cm}^{2}$. A field-emission scanning electron microscopy (FE-SEM; Hitachi S4800) was used to determine morphological structure and thickness (Kang et al 2009) of each PDMAcoated ITO.

\subsection{Electrochromic study of PDMA-coated ITO plastics}

Optical absorption spectra as well as optical kinetic responses of the PDMA/ITO electrode polymerized with various acids, were recorded on a spectrometer (Shimadzu, UV-1800). Measurements were carried out in a cuvette cell of $1 \mathrm{~cm}$ path length, assembled as an electrochemical cell with PDMA film-coated ITO plastic as the working electrode and stainless-steel wire as the counter electrode, in $0.01 \mathrm{M} \mathrm{H}_{2} \mathrm{SO}_{4}$ electrolyte solution. The scanned wavelength range was $400-800 \mathrm{~nm}$ (Neves et al 2004). To study the effect of the applied potential on the response time, the potentials applied to the PDMA/ITO were 0.5 , $1,1 \cdot 5,2,2 \cdot 5,3,3 \cdot 5,4,5$ and $10 \mathrm{~V}$ in the $0.01 \mathrm{M} \mathrm{H}_{2} \mathrm{SO}_{4}$ electrolyte solution. The effect of the electrolyte concentration on the response time was studied at the applied 
potential $3.5 \mathrm{~V}$ in various concentrations of $\mathrm{H}_{2} \mathrm{SO}_{4}\left(10^{-6}\right.$, $10^{-5}, 10^{-4}, 10^{-3}, 10^{-2}$ and $10^{-1} \mathrm{M}$ ).

\section{Results and discussion}

\subsection{FT-IR spectra of PDMA/ITO film}

The spectra of PDMA synthesized in oxalic $\left(\mathrm{H}_{2} \mathrm{C}_{2} \mathrm{O}_{4}-\right.$ PDMA), nitric ( $\left.\mathrm{HNO}_{3}-\mathrm{PDMA}\right)$ and hydrochloric ( $\mathrm{HCl}-$ PDMA) acids are shown in figure 1 . The peak at $\sim 3400 \mathrm{~cm}^{-1}$ can be attributed to the secondary $\mathrm{N}-\mathrm{H}$ stretching mode for the amine functional group. The band at $1570 \mathrm{~cm}^{-1}$ belongs to the $\mathrm{C}=\mathrm{N}$ and $\mathrm{C}=\mathrm{C}$ stretching modes of the benzenoid ring. The quinoid and benzenoid peaks of PDMA at $\sim 1490$ and $1580 \mathrm{~cm}^{-1}$ cannot be clearly observed. This may be due to the overlapping with the aromatic $\mathrm{C}=\mathrm{C}$ stretching bands ranging from 1400 to $1600 \mathrm{~cm}^{-1}$ (Neelgund et al 2008). The weak band at $\sim 1647 \mathrm{~cm}^{-1}$ is indicative of the presence of the carbonyl group $\mathrm{C}=\mathrm{O}$ contained in the oxalate ion (Patil et al 2004). The FT-IR spectrum of $\mathrm{HNO}_{3}-\mathrm{PDMA}$ includes an additional peak at $1384 \mathrm{~cm}^{-1}$ corresponding to the nitrate group acting as a counter ion with the protonated amine (Blinova et al 2009). The FT-IR results suggest that the acid-doped PDMA films are in the emeraldine and pernigraniline forms. In addition, the quinoid and benzenoid peaks appear in the spectra and the darkgreen synthesized PDMA films suggest the dominance of the emeraldine and pernigraniline forms of the aciddoped PDMA films.

\subsection{Thermogravimetric analysis}

Decomposition temperatures of TGA curves indicate that all PDMA samples decompose in the same three steps (Sapp et al 1998). The initial weight loss at $\sim 130{ }^{\circ} \mathrm{C}$ is due to the loss of water bound molecules or moisture. The next weight loss for PDMA at the temperature

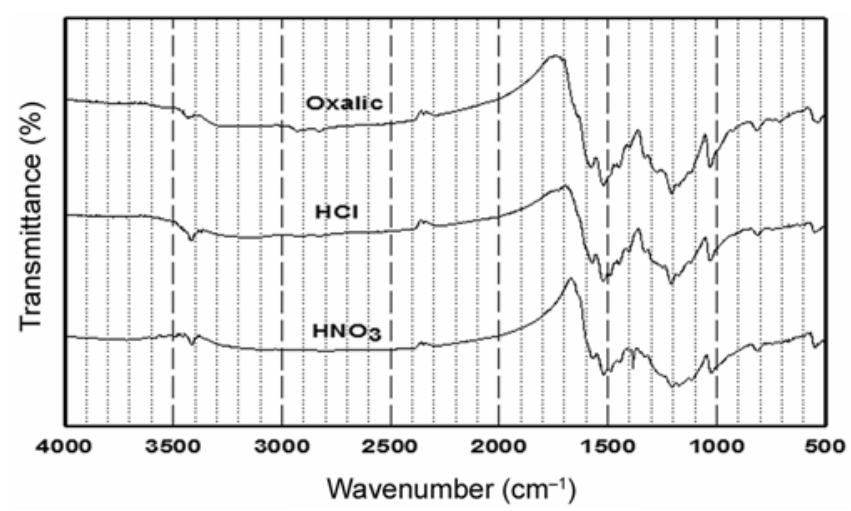

Figure 1. FT-IR spectra of PDMA film synthesized in oxalic acid, $\mathrm{HCl}$ and $\mathrm{HNO}_{3}$ as electrolyte solutions. $\sim 300{ }^{\circ} \mathrm{C}$ can be attributed to the removal of the dopant anions (Neelgund et al 2008). The third weight loss at $\sim 450^{\circ} \mathrm{C}$ indicates structural decomposition of the polymer chain.

\subsection{Morphology of PDMA surface}

Morphology of PDMA is different depending on the acids used (figure 2); the type of acid plays an important role in directing the morphology or in aligning the synthesized polymer. $\mathrm{H}_{2} \mathrm{C}_{2} \mathrm{O}_{4}$-PDMA shows a highly porous microfibre structure (Roy et al 2001), while the structure of $\mathrm{HNO}_{3}$-PDMA becomes a more disordered microfibre. The morphology of HCl-PDMA appears as an ordered tiny-granular aggregate. This is due to the smaller doping acid size $\left(\mathrm{Cl}^{-}<\mathrm{NO}_{3}^{-}<\mathrm{C}_{2} \mathrm{O}_{4}^{2-}\right)$; it can occupy more accessible spaces within the chain, leading to a more compact morphology, consistent with previous work (Melato et al 2009; Kiani et al 2012). Melato et al (2009) studied the electro-polymerization condition of poly(3,4-ethylenedioxythiophene) under different supporting electrolytes $\left(\mathrm{LiClO}_{4}, \mathrm{TBAClO}_{4}\right.$ and $\left.\mathrm{TBAPF}_{6}\right)$. The morphology of the film using $\mathrm{LiClO}_{4}$ was more compact than those of the other electrolytes, because the smaller cation size $\left(\mathrm{Li}^{+}\right)$ was more accessible to the polymer structure. The slightly higher size of $\mathrm{PF}_{6}^{-}$, occupied a larger space than $\mathrm{ClO}_{4}^{-}$leading to a less compact structure (Melato et al 2009). In all acids, as the polymerization continued, the surface morphology became more disordered and accompanied by particle aggregation. The polymerization time changed the morphology of the polymer film and induced particle fusion (Hernandez-Perez et al 2001). On the other hand, Hernandez-Perez et al (2001) investigated the morphology of polypyrrole (PPy) film which was prepared by potentiostatic and voltammetric methods on a platinum electrode at various electropolymerization times ( $50 \mathrm{~ms}, 200 \mathrm{~ms}$ and $5 \mathrm{~s}$ ). The fusion of PPy cluster formed a smooth compact film (Hernandez-Perez et al 2001).

\subsection{Thickness of PDMA on ITO substrate}

Thickness of the PDMA films was analysed by crosssectional FE-SEM monographs. At a longer polymerization time, the PDMA film is thicker (Kang et al 2009). PDMA was synthesized during the polymerization times of 3, 6 and $10 \mathrm{~min}$. The thicknesses of $\mathrm{H}_{2} \mathrm{C}_{2} \mathrm{O}_{4}-\mathrm{PDMA}$ film are $109 \pm 5,144 \pm 5$ and $164 \pm 8 \mathrm{~nm}$, respectively. The thicknesses of $\mathrm{HNO}_{3}-\mathrm{PDMA}$ films are $140 \pm 5$, $166 \pm 9,188 \pm 8 \mathrm{~nm}$, respectively. The thicknesses of the HCl-PDMA films are $78 \pm 3 \mathrm{~nm}$ and $104 \pm 2 \mathrm{~nm}$ at 6 and 10 min deposition time, respectively. The HCl-PDMA film produces the thinnest film at the same polymerization time because of the slow polymerization rate. The slow polymerization rate is due to the lack of oxygen atoms in the acid molecules causing no oxygen linkage 


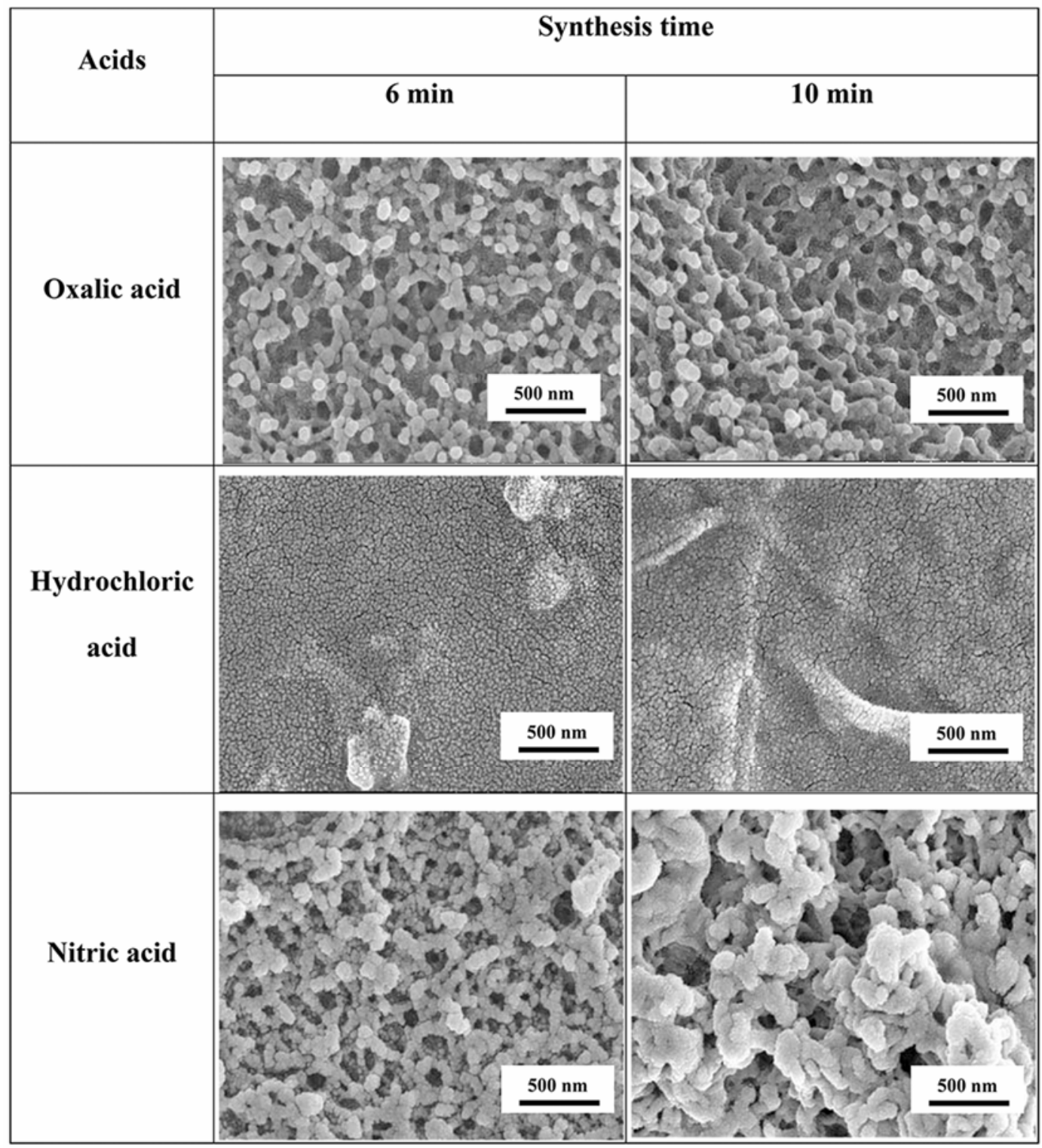

Figure 2. Surface morphology of PDMA film synthesized in oxalic acid, $\mathrm{HCl}$ and $\mathrm{HNO}_{3}$ as electrolyte solutions at 6 and 10 min deposition times.

between the ITO surface and the DMA monomer (Camalet et al 1998; Patil et al 2004).

\subsection{UV absorption spectrum of PDMA}

UV absorption spectra of the synthesized PDMA films, exhibit a band at $\lambda_{\max } \sim 750 \mathrm{~nm}$ corresponding to the pernigraniline form. At $-1 \mathrm{~V}$, the spectrum shows an absorption band at $\lambda_{\max }=480 \mathrm{~nm}$ corresponding to the reduced state (leucoemeraldine) which disappears upon oxidation (Neves et al 2004; Huang et al 2006).

\subsection{Colouration kinetics of PDMA}

3.6a Response and reversibility of poly(2,5-dimethoxyaniline) film: The absorption spectra of $\mathrm{H}_{2} \mathrm{C}_{2} \mathrm{O}_{4}-\mathrm{PDMA}$,
$\mathrm{HNO}_{3}-\mathrm{PDMA}$ and $\mathrm{HCl}-\mathrm{PDMA}$ films recorded at $1 \mathrm{~V}$ with 2 min interval in $0.01 \mathrm{M} \mathrm{H}_{2} \mathrm{SO}_{4}$ show two absorption bands at $\lambda_{\text {max }} \sim 480$ and $\sim 750 \mathrm{~nm}$. Figure 3(a and b) show the absorption spectra of $\mathrm{H}_{2} \mathrm{C}_{2} \mathrm{O}_{4}$-PDMA film obtained from the oxidation and reduction reactions, respectively. The band at $\lambda_{\max } \sim 480 \mathrm{~nm}$ corresponds to the reduced state (leucoemeraldine). This band disappears upon an oxidation reaction, while the band appearing at $\lambda_{\max } \sim 750 \mathrm{~nm}$ corresponds to the oxidation state of PDMA or the pernigraniline form (figure $3 a$ ). For the reduction process, under applied potential of $-1 \mathrm{~V}$ as shown in figure $3(\mathrm{~b})$, the band at $\lambda_{\max } \sim 750 \mathrm{~nm}$ disappears, while the band at $\lambda_{\max } \sim 480 \mathrm{~nm}$ is observed, because the transformation of the oxidized pernigraniline form to the reduced leucoemeraldine form. Thus, the PDMA film can be switched from yellow (leucoemeraldine form) to blue 
(pernigraniline form) and blue to yellow via the redox switching process under applied negative and positive potentials. The electrolyte type is not critical to the absorption spectra, where the absorption spectra of $\mathrm{HNO}_{3}-$ PDMA and HCl-PDMA are similar to that of $\mathrm{H}_{2} \mathrm{C}_{2} \mathrm{O}_{4}-$ PDMA, but it affects the response time.

3.6b Effect of testing potentials on response time: The study of the kinetic colouration of the PDMA-coated ITO electrode was carried out via the kinetic mode of a UV-Visible spectrometer. The wavelength $750 \mathrm{~nm}$, representing the oxidized state, was used to identify the response time and the optical contrast between the redox states.

The effect of the testing potentials $(1-3.5 \mathrm{~V})$ in $0.01 \mathrm{M}$ $\mathrm{H}_{2} \mathrm{SO}_{4}$ electrolyte on the reduction time, oxidation time and response time of $\mathrm{H}_{2} \mathrm{C}_{2} \mathrm{O}_{4}-\mathrm{PDMA}, \mathrm{HNO}_{3}-\mathrm{PDMA}$ and $\mathrm{HCl}-\mathrm{PDMA}$ films at various synthesis times are shown in figure 4 . The reduction time, oxidation time and response time decrease with increase in the electrical potential for all PDMA samples as the increase in electrical potential induces electrical conductivity and promote the redox process colour changing mechanism (Abd-Elwahed and Holze 2002). At 6 min synthesis time, the response time of PDMA decreases from 290 to $21 \mathrm{~s}$ for $\mathrm{H}_{2} \mathrm{C}_{2} \mathrm{O}_{4}-\mathrm{PDMA}$ film (figure 4a), 515 to $38 \mathrm{~s}$ for $\mathrm{HNO}_{3}-\mathrm{PDMA}$ film (figure $4 \mathrm{~b}$ ) and 182 to $3.7 \mathrm{~s}$ for HCl-PDMA film (figure 4c) as the applied potential increases from 1 to $3.5 \mathrm{~V}$. At the
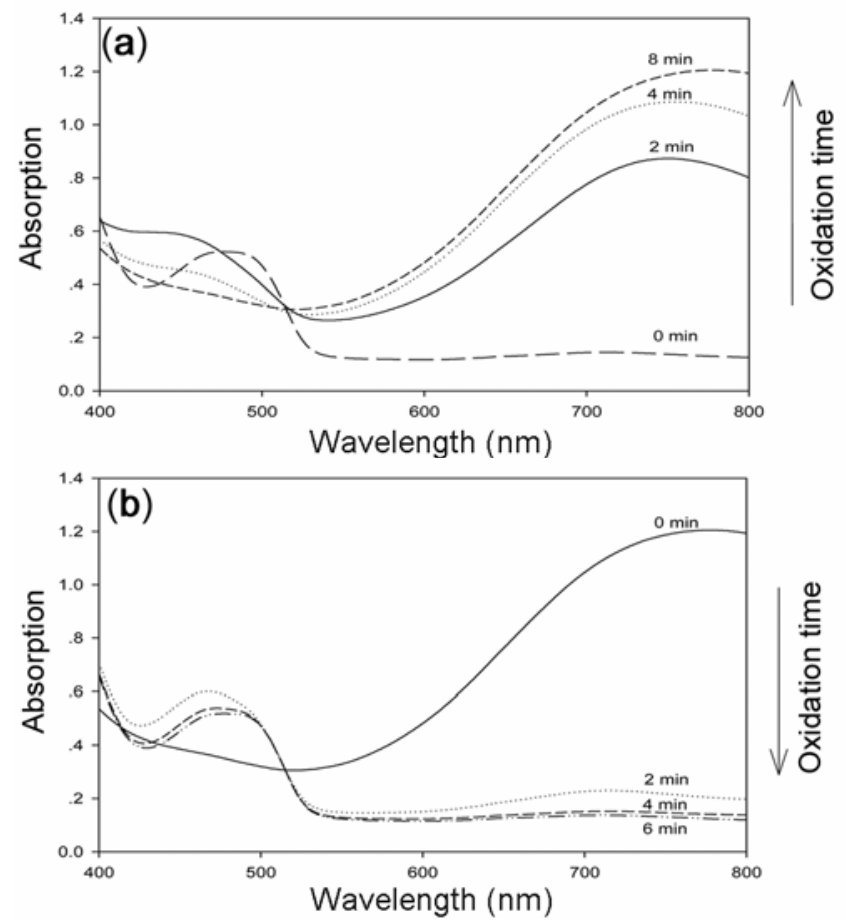

Figure 3. The absorption spectra of $\mathrm{H}_{2} \mathrm{C}_{2} \mathrm{O}_{4}$-PDMA synthesized at 3 min deposition time in $0.01 \mathrm{M} \mathrm{H}_{2} \mathrm{SO}_{4}$ : (a) oxidized state at the applied potential of $+1 \mathrm{~V}$ and (b) reduced state at the applied potential of $-1 \mathrm{~V}$.
10 min synthesis time, the response time of PDMA decrease from 385 to $25 \cdot 5 \mathrm{~s}, 1310$ to $35 \mathrm{~s}$ and 350 to $15 \mathrm{~s}$ for $\mathrm{H}_{2} \mathrm{C}_{2} \mathrm{O}_{4}$-PDMA, $\mathrm{HNO}_{3}$-PDMA and $\mathrm{HCl}-\mathrm{PDMA}$ films, respectively (figure 4 ), when the applied potential increases from 1 to $3.5 \mathrm{~V}$. The fastest response time of $\mathrm{H}_{2} \mathrm{C}_{2} \mathrm{O}_{4}-\mathrm{PDMA}$ and $\mathrm{HNO}_{3}$-PDMA films are $12 \cdot 8$ and $20 \mathrm{~s}$, respectively, for 3 min synthesis and at the testing potential of $3.5 \mathrm{~V}$ (figure $4(\mathrm{a}$ and $\mathrm{b})$ ). The faster response time for $\mathrm{HCl}-\mathrm{PDMA}$ film is $3.7 \mathrm{~s}$ of $6 \mathrm{~min}$ and at the testing potential shown in figure 4(c).

The results of the response time of PDMA from various acids indicate that the increase in the polymerization time contributes to the increase in the thickness of the PDMA films and a more compact structure, resulting in slower response time. Moreover, the $\mathrm{HCl}-\mathrm{PDMA}$ film shows the fastest response time $(3.7 \mathrm{~s})$ relative to other acids at the same synthesis time, because it produces the thinnest film and the smallest doping acid size resulting in a faster doping process (Palaniappan et al 2012). Furthermore, it is found that the $3.7 \mathrm{~s}$ response time of the $\mathrm{HCl}-\mathrm{PDMA}$ is faster than the ITO/PDMA|| $\mathrm{LiClO}_{4}$-PC-PEO $(400,000) \|$ $\mathrm{WO}_{3} / \mathrm{ITO}$ device (Huang et al 2002), since liquid electrolyte has greater ion mobility than gel electrolyte.

3.6c Effect of electrolyte concentration on response time: Since, the fastest response time for all acids was obtained at $3.5 \mathrm{~V}$, this potential was used to study the effect of electrolyte concentration on response time of PDMA. In addition, the $\mathrm{H}_{2} \mathrm{C}_{2} \mathrm{O}_{4}-\mathrm{PDMA}$ and $\mathrm{HNO}_{3}-$ PDMA films for $3 \mathrm{~min}$ and HCl-PDMA synthesized for 6 min showed the fastest response times, hence, these films were further used to study the effect of electrolyte concentration.

The PDMA-coated ITO plastics were tested at $3.5 \mathrm{~V}$ in various concentrations of $\mathrm{H}_{2} \mathrm{SO}_{4}$. Figure 5 shows that the increase in the electrolyte concentration from $10^{-6}$ to $10^{-2} \mathrm{M}$ results in a reduction of the response time from 460 to $13.5 \mathrm{~s}, 760$ to $36 \mathrm{~s}$ and 160 to $3 \cdot 7 \mathrm{~s}$ for $\mathrm{H}_{2} \mathrm{C}_{2} \mathrm{O}_{4}-$ PDMA, $\mathrm{HNO}_{3}-\mathrm{PDMA}$ and $\mathrm{HCl}-\mathrm{PDMA}$ films, respectively. The HCl-PDMA film is the thinnest, consequently, it has the fastest response time. In addition, the response time decreases with increasing $\mathrm{H}_{2} \mathrm{SO}_{4}$ concentration as a higher electrolyte concentration has more protons and higher mobility, resulting in a faster response time (Zhu and $\mathrm{Mu}$ 2001). Ram and co-workers (1997) studied the switching response time of poly(aniline-co- $O$ anisidine) film based on the effect of $\mathrm{HCl}$ concentration. They showed the decrease in response time with increase in $\mathrm{HCl}$ concentration. Furthermore, Habib and Glueck (1989) reported that the response time of tungsten oxide film decreased with increase in $\mathrm{LiClO}_{4}$ concentration. In both the cases, they explained that a higher acid concentration produced a higher amount of $\mathrm{H}^{+}$ion (from $\mathrm{HCl}$ ) or $\mathrm{Li}^{+}$(from $\mathrm{LiClO}_{4}$ ). The diffusion rate of $\mathrm{H}^{+}$or $\mathrm{Li}^{+}$insertion into the film played a major role in the electrochromic process. 

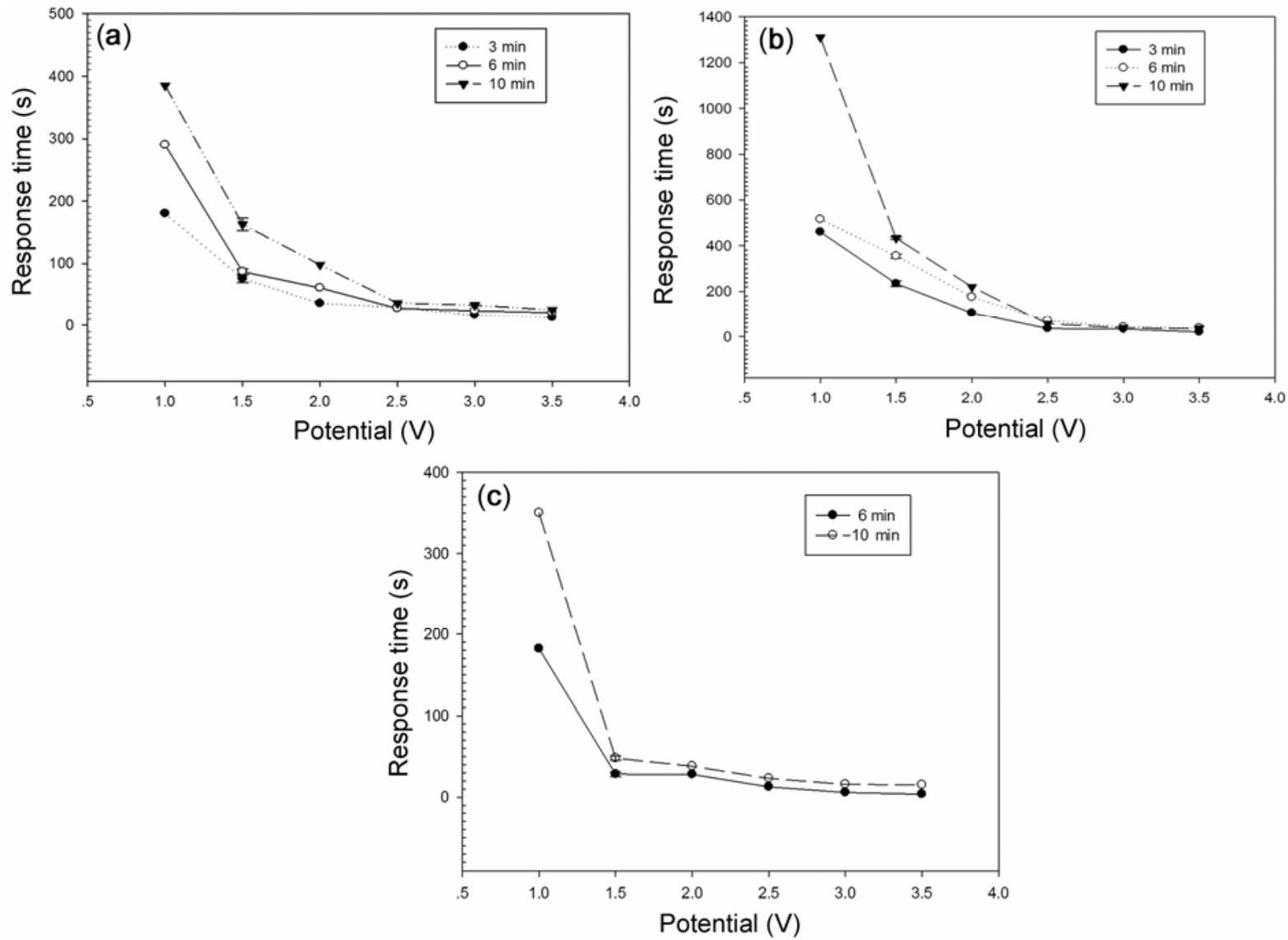

Figure 4. Effect of testing potential on response time at various synthesis times (a) $\mathrm{H}_{2} \mathrm{C}_{2} \mathrm{O}_{4}-\mathrm{PDMA}$; (b) $\mathrm{HNO}_{3}-\mathrm{PDMA}^{-}$ and (c) HCl-PDMA.

3.6d Effect of the type of acids and synthesis time on the optical contrast: High optical contrast is an important property of an efficient electrochromic polymer. In this study, the optical contrast ( $\triangle \mathrm{Abs}$ ) of PDMA/ITO was determined as the absorbance difference between the steady state values of the reduction and oxidation states. The optical contrasts of $\mathrm{H}_{2} \mathrm{C}_{2} \mathrm{O}_{4}-\mathrm{PDMA}_{2} \mathrm{HNO}_{3}-\mathrm{PDMA}$ and HCl-PDMA film at the 6 min deposition time are $0 \cdot 372 \pm 0.097,1.770 \pm 0.240$ and $2 \cdot 260 \pm 0 \cdot 360$, respectively. At the polymerization time of $10 \mathrm{~min}$, the optical contrasts of $\mathrm{H}_{2} \mathrm{C}_{2} \mathrm{O}_{4}-\mathrm{PDMA}, \mathrm{HNO}_{3}-\mathrm{PDMA}$ and $\mathrm{HCl}-$ PDMA films are $1 \cdot 170 \pm 0 \cdot 440,2 \cdot 010 \pm 0 \cdot 140$ and $2 \cdot 330 \pm$ $0 \cdot 300$, respectively. The optical contrasts of the PDMA films slightly increase, when the polymerization time increases from 6 to 10 min due to increase in film thickness (Camalet et al 1998). PDMA synthesized at the same synthesis time shows optical contrasts in the order of nitric acid > oxalic acid > hydrochloric acid. It is evident that the optical contrast depends on the thickness of PDMA film (Camalet et al 1998; Holt et al 2005). The highest contrast between the bleached and the coloured forms is observed at $\lambda=750 \mathrm{~nm}(\Delta T=73 \%)$, which is higher than that of an ITO/PDMA electrode $(\Delta T=23 \%)$ (Huang et al 2002). Kang et al (2009) studied the optical properties of PEDOT-PANI hybrid film based on the effect of polymerization time. The result showed that the optical contrast increased with increase in polymerization time. They explained that the polymerization time affected the film thickness and thus, the film optical contrast (Kang et al 2009). Holt et al (2005) reported the optical contrast of poly(phenylene vinylene) and PPV, based on the effects of applied voltage and salt type. The optical contrast of PPV increased with increase in applied voltage as the higher applied voltage created a greater film thickness, resulting in higher optical contrast. Furthermore, the type of anionic salt (TBA and triflate) affected the optical contrast, because it acted as a dopant (Holt et al 2005).

\subsection{Cyclic voltammetry (CV) of PDMA}

All PDMA films deposited on ITO show two main redox processes in which the first peak indicates the oxidation as related to the leucoemeraldine/emeraldine (yellow to green) transformation, and the second sharp peak corresponds to the emeraldine/pernigraniline (green to blue) transformation, consistent with previous studies (Gazotti et al 1997; Klink et al 2011). 
Cyclic voltammograms (CV) of $\mathrm{H}_{2} \mathrm{C}_{2} \mathrm{O}_{4}-\mathrm{PDMA}$ at various times are shown in figure 6. The $\mathrm{H}_{2} \mathrm{C}_{2} \mathrm{O}_{4}-\mathrm{PDMA}$ film synthesized at $10 \mathrm{~min}$ shows two redox peaks at $-0 \cdot 35 /-0 \cdot 85$ and $0 \cdot 95 / 1.00 \mathrm{~V}\left(E_{\mathrm{pa}} / E_{\mathrm{pc}}\right)$. There are two reduction peaks which appear at 0.80 and $0.85 \mathrm{~V}$ for $\mathrm{H}_{2} \mathrm{C}_{2} \mathrm{O}_{4}$-PDMA film synthesized at $6 \mathrm{~min}$ and 0.65 and $0.90 \mathrm{~V}$ for $\mathrm{H}_{2} \mathrm{C}_{2} \mathrm{O}_{4}-\mathrm{PDMA}$ film synthesized at $3 \mathrm{~min}$. The oxidation peaks appear at -0.55 and $-0.40 \mathrm{~V}$ for the 6 and 3 min deposition times, respectively. In this work, it is difficult to observe two oxidation peaks because of the anionic effect (Palys et al 2000) hindering the polymer oxidation by the large anion $\left(\mathrm{C}_{2} \mathrm{O}_{4}^{2-}\right)$ resulting in the board peak as previously shown by Palys et al (2000). Furthermore, they reported the shapes of PDMA cyclic voltammograms strongly depended on the anion type $\left(\mathrm{ClO}_{4}^{-}, \mathrm{SO}_{4}^{-}, \mathrm{Cl}^{-}\right.$and $\left.\mathrm{CClO}_{3} \mathrm{COO}^{-}\right)$. The oxidation peak current increases, while the reduction peak current decreases with increasing polymerization time, resulting

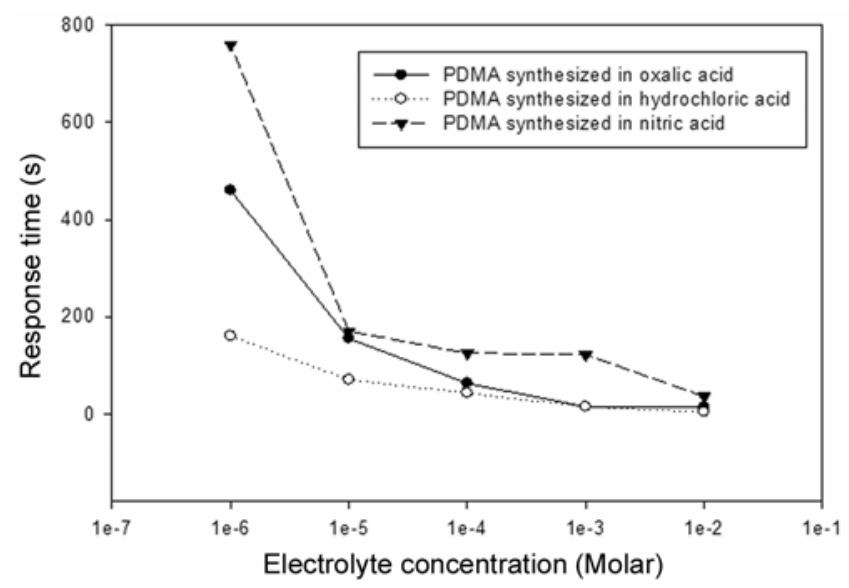

Figure 5. Effect of $\mathrm{H}_{2} \mathrm{SO}_{4}$ concentration on response time at $3.5 \mathrm{~V}$ of PDMA coated electrochemically polymerized ITO.

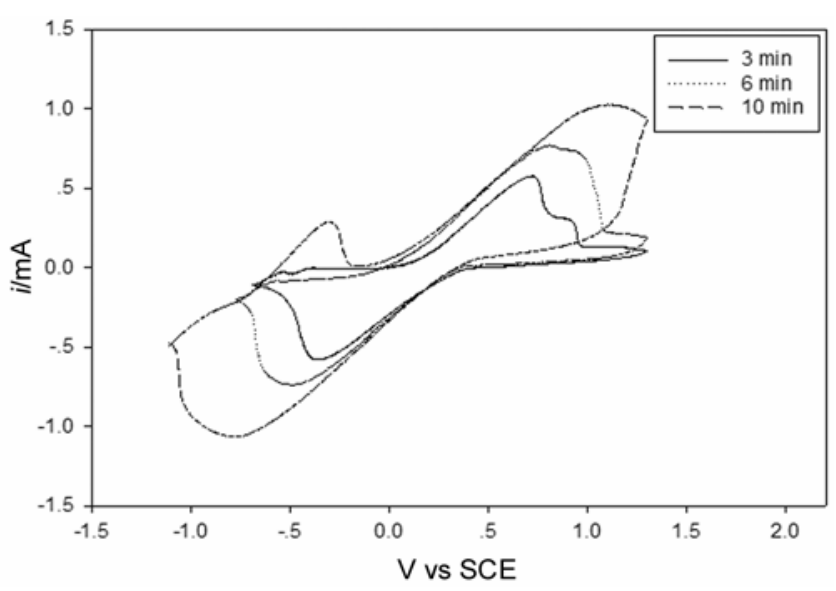

Figure 6. Cyclic voltammograms of $\mathrm{H}_{2} \mathrm{C}_{2} \mathrm{O}_{4}-\mathrm{PDMA}$ film at 3,6 and 10 min deposition times within the potential range of -1 to $1.5 \mathrm{~V}$; a scan rate of $10 \mathrm{mV} / \mathrm{s}$ and a $0.01 \mathrm{M}$ of $\mathrm{H}_{2} \mathrm{SO}_{4}$ electrolyte solution background. in the expansion of the current-potential curve area due to the increase in film thickness or a higher specific capacitance (Chiu et al 1992; Sun et al 2013). As the polymerization time increases, the oxidation-reduction potentials of PDMA of all acids shift to being more positive and negative, due to the greater diffusion times of the counter ion for the redox reaction through the thicker films. Chui et al (1992) studied the effect of polypyrrole film thickness on cyclic voltammograms. The current-potential curve expanded and the potential difference $\left(\Delta E_{\mathrm{p}}=\right.$ $\left.E_{\mathrm{pa}}-E_{\mathrm{pc}}\right)$ increased with the increase in film thickness as the amount of dopant increased. However, they obstructed further anions permeation, thus, higher potential was required for anion movement on the film.

On the other hand, Elmansouri et al (2007, 2009) showed that the oxidation potentials and currents of different supporting electrolytes depended on the nature and size of the anion present in the solution. The oxidation current was proportional to the speed of the electropolymerization reaction, this suggested faster growth kinetics. The oxidation current increased with increase in film thickness, as a function of the growth kinetics (Elmansouri et al 2007, 2009).

\section{Conclusions}

The synthesized PDMA films show reversible colour change from yellow to green representing the transition between the leucoemeraldine (reduced) state and emeraldine (oxidized) state which depend on the switching potentials. The PDMA/ITO electrochemically polymerized samples have mostly the same structural properties; the only difference is that the FT-IR bands show different counter ions of the oxalate and nitrate groups acting as counter ions with the protonated amine. The important differences of the PDMA synthesized in various acids at the same polymerization time are morphology and thickness of PDMA films, both factors lead to variations in the response time and the optical contrast. The increase of applied potential $(1-3.5 \mathrm{~V})$ and the $\mathrm{H}_{2} \mathrm{SO}_{4}$ electrolyte concentration $\left(10^{-6}-10^{-1} \mathrm{M}\right)$ contributed significantly to the decrease in the response time. With the increase of the polymerization time, the cyclic voltammetry showed a shift of the oxidation-reduction potentials of PDMA from all acids to being more positive and negative due to the greater diffusion time of the counter ion for the redox reaction through the thicker films.

\section{Acknowledgements}

The authors would like to acknowledge financial support from the Conductive and Electroactive Polymers Research Unit, the Petroleum and Petrochemical College, Chulalongkorn University, the Thailand Research Fund (TRFRTA), and the Royal Thai Government. 


\section{References}

Abd-Elwahed A and Holze R 2002 Synth. Met. 13161

Bange K 1999 Sol. Energy Mater. Sol. Cells 581

Blinova N V, Stejskal J, Trchova M, Sapurina I and Marjanovic G C 2009 Polym. 5050

Brotherson I D, Mudigonda D S K, Ocborn J M, Belk J, Chen J, Loveday D C, Boehme J L and Ferraris J P 1999 Electrochim. Acta 442993

Camalet J L, Lacroix J C, Aeiyach S, Ching K C and Lacaze P C 1998 Synth. Met. 93133

Chiu H-T, Lin J-S and Shiau J-N 1992 J. Appl. Electrochem. 22 522

Elmansouri A, Outzourhot A, Lachkar A, Hadik N, Achour M E, Abouelaoualim A, Berrada K and Ameziane E L 2007 Act. Pass. Electron. Comp. 71

Elmansouri A, Outzourhot A, Lachkar A, Hadik N, Achour M E, Abouelaoualim A, Berrada K and Ameziane E L 2009 Synth. Met. 159292

Gazotti W A J, Jannini M J D M, Torres S I C D and Paoli M A D 1997 J. Electroanal. Chem. 440193

Habib M A and Glueck D 1989 Sol. Energy Mat. 18127

Hernandez-Perez T, Morales M, Batina N and Salmon M 2001 J. Electrochem. Soc. 148 C369

Holt A L, Leger J M and Carter S A 2005 Appl. Phys. Lett. 861

Huang L M, Huang G C and Wen T C 2006 J. Polym. Sci.: Part A: Polym. Chem. 446624

Huang L M, Wen T C and Gopalan A 2002 Mater. Chem. Phys. 77726

Kang J H, Jioha Y, Minpaek S, Juhwang S and Hochoy J 2009 Sol. Energy Mater. Sol. Cells 932040

Khan A A, Alam M M and Mohammad F 2003 Electrochim. Acta 482463

Kiani F, Rostami A A, Omrani A, Sharifirad M, Koohyar F and Moradi A 2012 Eur. Online J. Nat. Soc. Sci. 155
Kim Y, Do J, Kim E, Clavier G, Galmiche L and Audebert P 2009 J. Electroanal. Chem. 632201

Klink M J, Iwuoha E I and Ebenso E E 2011 Int. J. Electrochem. Sci. 62429

Mavundla S E, Malgas G F, Baker P and Iwuohab E I 2008 Electroanalysis 202347

Melato A L, Mendonca M H and Abrantes L M 2009 J. Solid State Electrochem. 13417

Montazami R, Jain V and Heflin R J 2010 Electrochim. Acta 56 990

Neelgund G M, Hrehorova E, Joyce M and Bliznyuk V 2008 Polym. Int. 571083

Neves S, Santos R F, Gazotti W A and Fonseca C P 2004 Thin Solid Films 460300

Palaniappan S, Chang Y-T, Liu C-M and Manisankar P $2012 \mathrm{~J}$. Appl. Polym. Sci. 1244281

Patil V, Sainkar S R and Patil P P 2004 Synth. Met. 140 57

Palys B, Kudelski A, Stankiewicz A and Jackowska K 2000 Synth. Met. 108111

Peters A T and Freeman H S 1991 Colour chemistry: The design and synthesis of organic dyes and pigments (Baraking Essex, UK: Elsevier Applied Science Publishing) p. 193

Ram M K, Maccioni E and Nicolini C 1997 Thin Solid Films 30327

Ramakrishnan S 1997 Resonance 248

Roy C B, Gupta D M, Bhowmik L and Ray K J 2001 Bull. Mater. Sci. 24389

Sapp S A, Sotzing G A and Reynolds J R 1998 Chem. Mater. 102101

Sarkar N, Ram M, Sarkar A, Narizzano R, Paddeu S and Nicolini C 2000 Nanotechnol. 1130

Sonmez G 2005 Chem. Commun. 425251

Sun M, Wang W, He B, Sun M, Liu W, Ge H, Zhang Q and Sun F 2013 J. Appl. Polym. Sci. 4672

Zhu H and Mu S 2001 Synth. Met. 123293 